\title{
Multiple Circuits Relaying Primate Parallel Visual Pathways to the Middle Temporal Area
}

\author{
Jonathan J. Nassi and Edward M. Callaway \\ Systems Neurobiology Laboratories, The Salk Institute for Biological Studies, La Jolla, California 92037
}

\begin{abstract}
Parallel pathways in the primate visual system parse the sensory signal into magnocellular (M), parvocellular (P), and koniocellular (K) streams. These pathways remain anatomically separate and distinct from their origination in different retinal ganglion cell types, through distinct layers of the lateral geniculate nucleus, and into primary visual cortex (V1), with the M pathway terminating primarily in layer $4 \mathrm{C} \alpha$, the $\mathrm{P}$ pathway in layer $4 \mathrm{C} \beta$, and the $\mathrm{K}$ pathway in the cytochrome oxidase blobs of layer $2 / 3$. Recent studies indicate that outputs from V1 are less compartmental than previously thought, making it difficult to assess the contributions of $\mathrm{M}$ and P pathways to areas beyond $\mathrm{V} 1$ in the dorsal and ventral streams. Here we use rabies virus as a retrograde transsynaptic tracer to study the contributions of $\mathrm{M}$ and P pathways to areas middle temporal (MT), V3, and V2 of macaque monkey. We find that, although disynaptic inputs through layer $4 \mathrm{C}$ of V1 to dorsal stream area MT are dominated by the M pathway, within an additional three synapses MT receives a substantial P input. This P input is unlikely to reach MT via V3, which we show also receives disynaptic inputs dominated by the M pathway. We find that disynaptic inputs to V2, however, can be more balanced and may carry convergent M and P input to MT. Our observations provide evidence for multiple pathways from V1 to MT, with varying degrees of M and P convergence. Each pathway likely provides functionally specialized information to MT and dorsal stream visual processing.
\end{abstract}

Key words: macaque; vision; retrograde labeling; transsynaptic; rabies virus; primary visual cortex; magnocellular; parvocellular

\section{Introduction}

The primate visual cortex is divided into multiple areas and relatively independent dorsal and ventral streams (DeYoe and Van Essen, 1988; Livingstone and Hubel, 1988; Zeki and Shipp, 1988; Merigan and Maunsell, 1993). Dorsal stream cortical areas are specialized for analyses of motion and spatial relationships, whereas ventral stream cortical areas are specialized for processing of fine form and color information. It long has been attractive to link the magnocellular (M) pathway to the dorsal stream and the parvocellular $(\mathrm{P})$ pathway to the ventral stream, mainly based on similarities in their respective visual response profiles, yet other theoretical considerations suggest that both $\mathrm{M}$ and $\mathrm{P}$ pathways can provide useful information for computations conducted in both dorsal and ventral visual areas (Merigan and Maunsell, 1993; Van Essen and Deyoe, 1994). Furthermore, anatomical and functional studies have indicated that the early parallel visual pathways converge significantly via the local circuitry within V1 and onto both dorsal and ventral stream cortical areas

\footnotetext{
Received Sept. 15, 2006; revised 0ct. 27, 2006; accepted Nov. 1, 2006.

This work was supported by National Institutes of Health Grants EY 010742 (E.M.C.) and 5 T32 AG00216 and 2 T32 MH20002 (J.J.N.). We thank Dr. Roberta Kelly for crucial advice in the design and interpretation of these experiments and for participating in the execution and analysis of control experiments testing the rate of spread of rabies virus in the primate motor system. We also thank Dr. Donald Lodmell for providing the CVS-11 strain of rabies virus and antibodies to the rabies nucleocapsid; Cecelia Kemper for technical assistance with structural magnetic resonance imaging; Mauricio De La Parra for assistance with animal care and surgical procedures; and Drs. David Lyon, Greg Horwitz, and Vivien Casagrande for comments on this manuscript.

Correspondence should be addressed to Edward M. Callaway, Systems Neurobiology Laboratories, The Salk Institute for Biological Studies, 10010 North Torrey Pines Road, La Jolla, CA 92037. E-mail: callaway@salk.edu. DOI:10.1523/JNEUROSCI.4044-06.2006

Copyright $\odot 2006$ Society for Neuroscience $\quad$ 0270-6474/06/2612789-10\$15.00/0
}

(Merigan and Maunsell, 1993; Callaway, 2005; Sincich and Horton, 2005).

Identifying the circuits that mediate the complex interactions between $\mathrm{M}$ and $\mathrm{P}$ pathways and understanding how they contribute to perception are critical to our understanding of the primate visual system. For example, it is unclear how and to what extent the $\mathrm{M}$ and $\mathrm{P}$ pathways contribute to the dorsal stream motionprocessing area middle temporal (MT). MT receives its main ascending input via layer $4 \mathrm{C}$ and, subsequently, layer $4 \mathrm{~B}$ of $\mathrm{V} 1$ (Shipp and Zeki, 1989a). Cells projecting directly from layer 4B of $\mathrm{V} 1$ to MT are thought to receive input predominantly from M-recipient layer $4 \mathrm{C} \alpha$, yet layer $4 \mathrm{~B}$ cells can receive input either from layer $4 \mathrm{C} \alpha$ alone or from both layer $4 \mathrm{C} \alpha$ and P-recipient layer 4C $\beta$ (Yabuta et al., 2001). Furthermore, MT-projecting cells in layer $4 \mathrm{~B}$ of $\mathrm{V} 1$ are intermixed spatially with separate populations of cells in layer $4 \mathrm{~B}$ of $\mathrm{V} 1$ that project to $\mathrm{V} 3$ and the cytochrome oxidase (CO) thick stripes of V2 (Maunsell and van Essen, 1983; Burkhalter et al., 1986; Shipp and Zeki, 1989b; Sincich and Horton, 2003). These populations may, in turn, provide indirect projections to MT, yet the absence of clear compartmentalization in V1 (Sincich and Horton, 2002; Xiao and Felleman, 2004) as well as heterogeneity within compartments has made it difficult to determine the contributions of $\mathrm{M}$ and $\mathrm{P}$ pathways to each of these specialized cortical circuits.

Transsynaptic retrograde labeling with rabies virus, however, provides a means of identifying directly the cells in M-recipient layer $4 \mathrm{C} \alpha$ and $\mathrm{P}$-recipient layer $4 \mathrm{C} \beta$ presynaptic to extrastriate projecting neurons in $\mathrm{V} 1$. We made multiple injections of rabies virus into $\mathrm{MT}, \mathrm{V} 3$, and $\mathrm{V} 2$ to assess the contributions of $\mathrm{M}$ and $\mathrm{P}$ pathways to MT. We find that, although the most direct input 
through layer 4C of V1 to MT is dominated by the M pathway, less direct input can be more balanced, carrying a substantial $\mathrm{P}$ input to MT.

\section{Materials and Methods}

Surgical procedures. Six adult macaque monkeys were used, following procedures approved by the Salk Institute Animal Care and Use Committee. In addition, all procedures using rabies virus were conducted by using biosafety level 2 precautions as described previously (Kelly and Strick, 2000).

A 1.5 tesla Siemens (Erlangen, Germany) Symphony magnetic resonance scanner (University of California, San Diego Hillcrest Medical Center/Tenet Magnetic Resonance Institute, San Diego, CA) was used to obtain a full coronal (JNM1, JNM10, and JNM11) or parasagittal (JNM3 and JNM4) series of 1-mm-thick images for each monkey used for injections into MT or V3. Resulting structural images were used to calculate stereotaxic coordinates for our injections either along the posterior bank of the superior temporal sulcus (STS) for MT injections or the annectent gyrus for V3 injections. This was not necessary for our V2 injections, because we simply targeted the opercular surface just posterior to the lip of the lunate sulcus.

MT was targeted in three monkeys, JNM1, JNM10R (right hemisphere of JNM10), and JNM11. MT injections were made by using Hamilton syringes with a 30 gauge needle. In monkey JNM1 three penetrations were aimed at the posterior bank of the STS. Approximately $0.4 \mu \mathrm{l}$ of the challenge virus strain-11 (CVS-11) strain of rabies virus (see below, Rabies virus strain and speed of transport) was injected at each of four depths spaced $0.5 \mathrm{~mm}$ apart. In addition, one of the injection sites included 10\% rhodamine dextran (10,000 MW; Molecular Probes, Carlsbad, CA) in the solution of rabies virus. In monkey JNM10R two penetrations were made into the posterior STS, and $0.4 \mu \mathrm{l}$ of virus was injected at five different depths. In monkey JNM11 the injections were made similarly as in JNM10R.

V3 was targeted in two monkeys, JNM3 and JNM4. V3 injections were made by using Hamilton syringes with a 30 gauge needle. In monkey JNM3 two penetrations were aimed at the annectent gyrus, spaced $\sim 1$ $\mathrm{mm}$ apart mediolaterally. Approximately $0.3 \mu \mathrm{l}$ of virus, including $10 \%$ rhodamine dextran, was injected at each of three depths spaced $0.5 \mathrm{~mm}$ apart. In monkey JNM4 the injections were made similarly as in JNM3.

V2 was targeted in two monkeys, JNM10L (left hemisphere of JNM10) and JNM13. V2 injections were made by using glass micropipettes (tip diameter, $\sim 30 \mu \mathrm{m}$ ), and pressure was applied by a Picospritzer. In monkey JNM10L seven penetrations were made along the opercular surface, perpendicular to the cortical surface, just posterior to the lip of the lunate sulcus. Penetrations were separated by $\sim 5 \mathrm{~mm}$ mediolaterally. Approximately $0.3 \mu$ l of virus was injected at each of three depths spaced $0.5 \mathrm{~mm}$ apart (0.4, 0.8, and $1.2 \mathrm{~mm}$ deep). In monkey JNM13 10 injections were made similarly as in JNM10L, except with mediolateral separation between penetrations of $\sim 2 \mathrm{~mm}$.

Rabies virus strain and speed of transport. To trace disynaptic connections to areas MT, V3, and V2, we injected the CVS-11 strain of rabies virus and allowed a survival time of $3 \mathrm{~d}$. It is important to note that different preparations of rabies virus, including those of the same strain, can spread through the nervous system at different rates, mainly dependent on the passage history of the virus (Morimoto et al., 1998; Kelly and Strick, 2000). The particular preparation of the CVS-11 rabies virus that we used was obtained from Dr. Donald Lodmell, Rocky Mountain Laboratory (Hamilton, MT), and was passaged four times in mouse brain, followed by five times in cultured chicken embryo-related cells.

On the basis of the similarity in strain and passage history between the virus we used and the CVS-11 rabies virus used by Kelly and Strick (2003), we expected our virus to spread only disynaptically in $3 \mathrm{~d}$ and up to five synapses in $6 \mathrm{~d}$. To test the rate of spread of our virus explicitly, we repeated the experiments of Kelly and Strick (2003), injecting virus into motor cortex (M1) of the macaque monkey, as described previously (Nassi et al., 2006). These control experiments confirmed that the virus we injected into MT, V3, and V2 would travel only disynaptically within the $3 \mathrm{~d}$ survival time and up to five synapses within the $6 \mathrm{~d}$ survival time.
Histology. After 3 d survival time ( $6 \mathrm{~d}$ survival in the case of JNM11) the animals were killed and perfused with $4 \%$ paraformaldehyde, and their brains were removed. Sections were cut at $40 \mu \mathrm{m}$ on a freezing microtome parasagittally (JNM1, JNM3, JNM4, JNM10, JNM11) or coronally (JNM13). First a series of every 12th section was processed for both $\mathrm{CO}$ and rabies immunohistochemistry. We used this initially processed series to determine the extent of label in $\mathrm{V} 1$ and to select specific regions for more extensive processing. Each section was stained first for CO, followed by rabies immunostaining. Immunohistochemistry for the rabies nucleocapsid was performed by using the anti-nucleocapsid mouse monoclonal antibody (gift from Dr. Lodmell), the biotinylated horse anti-mouse secondary antibody (Vector Laboratories, Burlingame, CA), and an $\mathrm{ABC}$ avidin-peroxidase kit (Vector Laboratories) and was revealed via a diaminobenzidine $(\mathrm{DAB})$ reaction enhanced with nickel and cobalt (black reaction product). After cell count reconstructions the same sections then were stained for Nissl substance to determine the border between layers $4 \mathrm{C} \alpha$ and $4 \mathrm{C} \beta$.

For cases JNM1, JNM10R, and JNM11 a series of cortical sections that included the STS was processed for myelin, CO, or Nissl substance. Anatomical features of MT (Van Essen et al., 1981; Tootell et al., 1985), such as heavy and uniform myelination (particularly in deeper layers), dark and patchy $\mathrm{CO}$ staining, greater cortical thickness, and relative position on the posterior bank of the STS, were used to verify that injections were confined to area MT (see Figs. $1 A, B, 2 A$ ). For cases JNM3 and JNM4 a series of cortical sections that included the annectent gyrus was processed for myelin, CO, or Nissl substance. Anatomical features of V3 (Van Essen et al., 1986), such as heavy and uniform myelination (particularly in deeper layers) and distance from the V1/V2 border, were used to verify that injections were confined to V3 (see Fig. $4 A, B$ ). For cases JNM10L and JNM13 a series of cortical sections was processed for $\mathrm{CO}$ to visualize the V1/V2 border and to verify that injections were confined to V2 (see Fig. $5 A$ ).

In the MT and V3 injections our needle penetrations entered the white matter directly underneath cortex. Previous studies have shown that rabies virus uptake along cut peripheral axons is inefficient compared with uptake at axon terminals (Ugolini, 1995; Kelly and Strick, 2000), and rabies uptake along cut central axons has not been demonstrated. In addition, we have made multiple MT injections of a glycoprotein-deleted rabies virus, which does not transport transsynaptically, that have involved white matter in a similar way to the injections in this study. We found no evidence of white matter uptake in these cases, with retrogradely labeled cells localized to layers $4 \mathrm{~B}$ and 6 in V1, exactly what we would expect from an injection in cortical MT (Shipp and Zeki, 1989a). Furthermore, we have shown in previously published work a close retinotopic correspondence between our label in V1 and lateral geniculate nucleus (LGN) after injections into MT (Nassi et al., 2006). These data show convincing evidence that our injections were localized to cortical $\mathrm{MT}$ and not the underlying white matter or optic radiations. In both V3 cases all of our retrograde label was confined to the dorsal one-half of the calcarine sulcus and showed a strikingly different pattern from what we observed after injections into V2, making us confident that our injections were confined to V3 and did not involve white matter uptake or spread of virus to nearby cortical visual areas.

Data analysis. Positions of neuronal cell bodies labeled with rabies virus were plotted with Neurolucida software (MicroBrightField, Williston, VT). Only cell bodies with a visible nucleus were counted. For cases with $3 \mathrm{~d}$ survival only regions of $\mathrm{V} 1$ in which disynaptic label was densest were reconstructed. We defined these regions as those that had maximum label in layer $4 \mathrm{C}$, because this was the only layer affording certain identification of disynaptic labeling. Once a boundary contour was drawn around a region of densest disynaptic label, the cells were visualized and plotted with a $40 \times$ objective, using automatic motorized scanning of the defined region. Reconstructions of the laminar boundaries of V1 were aided by CO staining of the same sections that were stained for rabies virus with $\mathrm{DAB}$ (for an example of a section processed for rabies and $\mathrm{CO}$, see Fig. $1 C$ ). Reconstructions of the laminar boundary between layers $4 \mathrm{C} \alpha$ and $4 \mathrm{C} \beta$ were aided by Nissl staining of these same sections after cell count reconstructions. LGN afferents have been shown to terminate in a pattern that corresponds well with the border visualized with 
a Nissl stain, with magnocellular axons occupying more than one-half of layer 4C (Blasdel and Lund, 1983).

Quantification of the laminar distribution of labeled cells was performed in MatLab (MathWorks, Natick, MA). Three nonadjacent reconstructions were analyzed from each region of V1 label. The numbers of labeled cells were summed across the three reconstructions within a region, and the resultant laminar proportions from each region were averaged across regions within the same animal and then across animals with the same cortical injection target.

\section{Results}

We used rabies virus as a transsynaptic retrograde tracer to study disynaptic connections from V1 to areas MT, V3, and V2 of macaque monkey. In particular, we were interested in delineating the contributions of $\mathrm{M}$ and $\mathrm{P}$ pathways by looking at the proportion of disynaptic label in layers $4 \mathrm{C} \alpha$ and $4 \mathrm{C} \beta$ of V1 after injections of rabies virus into either MT itself or into V3 or V2, which can provide MT with less direct V1 input (Maunsell and van Essen, 1983; Shipp and Zeki, 1989b). Physiological recordings have confirmed that cells within layers $4 \mathrm{C} \alpha$ and $4 \mathrm{C} \beta$ have visual response properties dominated by the $\mathrm{M}$ and $\mathrm{P}$ layers of the LGN from which they receive their feedforward, ascending input (Blasdel and Fitzpatrick, 1984). Therefore, contributions from the $\mathrm{M}$ and $\mathrm{P}$ pathways to extrastriate cortex could be assessed directly, based on the proportion of disynaptic label in $\mathrm{M}$-dominated layer $4 \mathrm{C} \alpha$ and $\mathrm{P}$-dominated layer $4 \mathrm{C} \beta$.

Studies in both rodents and primates have shown that rabies virus spreads retrogradely across synapses in a time-dependent manner (Ugolini, 1995; Kelly and Strick, 2000). At 3 d after injection the particular strain and preparation of rabies virus that was used in our experiments (see Materials and Methods) (Kelly and Strick, 2003) has time to transport across one synapse and infect neurons disynaptic to the injection site. The virus has time to transport across up to one additional synapse with each subsequent day of survival. Although the rabies virus shows no apparent preference for any particular cell type or size, the rate of transport does depend on strength of connections, leaving open the possibility that with a $3 \mathrm{~d}$ survival time some weak disynaptic connections remained unlabeled (Ugolini, 1995). We therefore chose a $3 \mathrm{~d}$ survival time for most of our experiments to make it quite unlikely that virus would spread past neurons disynaptic to our injection site. Additionally, in a single experiment we chose a $6 \mathrm{~d}$ survival time to allow virus to spread up to five synapses retrograde to the injection site.

We assessed disynaptic inputs to areas MT, V3, and V2 by making injections of the CVS-11 strain of rabies virus ( $3 \mathrm{~d}$ survival) into MT of two monkeys, V3 of two monkeys, and V2 of two monkeys. Additionally, in one monkey we made injections into MT with a $6 \mathrm{~d}$ survival time to assess inputs to MT up to five synapses away. We begin by describing detailed results for injections of rabies virus into MT, followed by V3 and then V2. Injections of rabies virus were targeted to cortical area MT of two macaque monkeys by using stereotaxic coordinates of the posterior bank of the STS obtained via structural magnetic resonance images. After a $3 \mathrm{~d}$ survival period the animals were perfused, and the brains were sectioned and stained for CO and an antibody against the rabies nucleocapsid protein (see Materials and Methods). The locations of the unilateral injections were confirmed histologically to be confined to MT (Fig. 1A,B) (see Materials and Methods). The needle penetration could be seen within the region of dense and uniform myelination along the posterior bank of the STS, and in an adjacent rabies-stained section the densest label was found in this same region (Fig. $1 A, B$ ). After the examination of histological sections, extensive label was found in all
A Myelin Stained MT Injection Site

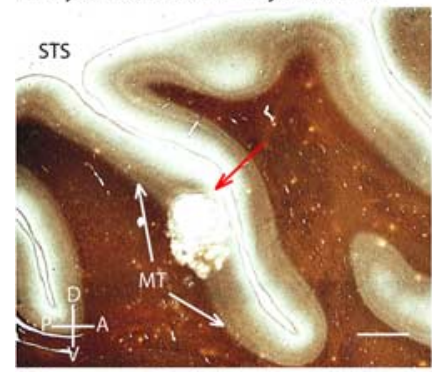

B Rabies Stained MT Injection Site

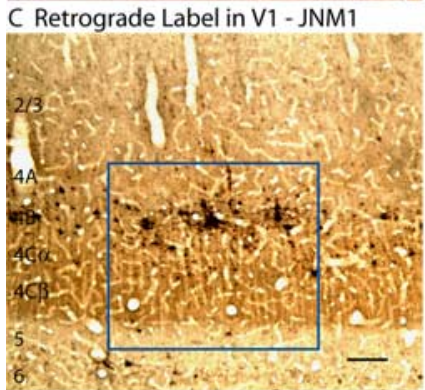

E Retrograde Label in V1 - JNM1

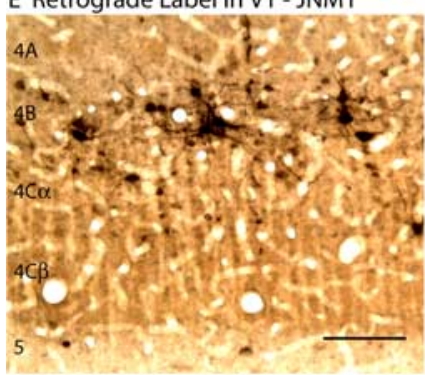

F Laminar Distribution of Label in V1 60

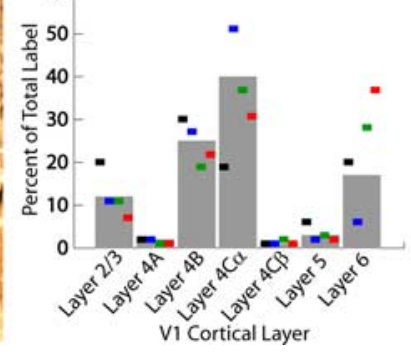

Figure 1. Retrogradely labeled neurons in V1 after a $3 \mathrm{~d}$ survival injections of rabies virus in cortical area MT. A, A montage of digitally photographed images of a single parasagittally cut cortical section stained for myelin showing the location of the rabies-injected region (red arrow) in the uniformly dense myelination of area MT (white arrows) along the posterior bank of the STS. $\boldsymbol{B}$, A montage of digitally photographed images of an adjacent parasagittal cortical section to that in $\boldsymbol{A}$ stained for the nucleocapsid protein of the rabies virus (black). D, Dorsal; $V$, ventral; $P$, posterior; $A$, anterior. Scale bars: $\boldsymbol{A}, \boldsymbol{B}, 2 \mathrm{~mm}$. $\boldsymbol{C}, \boldsymbol{D}$, Parasagittally cut cortical sections of $V 1$ from cases JNM1 ( $\boldsymbol{C}$ ) and JNM10R ( $\boldsymbol{D})$ stained for the nucleocapsid protein of the rabies virus (black) and for cytochrome oxidase (CO; brown). The bottom of the image in $C$ is cropped at the layer $6 /$ white matter border, and $\sim 10 \%$ of layer 6 is cropped at the bottom of the image in $\boldsymbol{D}$. Cortical layers are indicated. $\boldsymbol{E}$, Higher magnification image of the location indicated by the blue rectangle in $\boldsymbol{C}$ of rabies-labeled cells in layers $4 B$ and $4 C \alpha$ of V1, but not $4 C \beta$. Scale bars: $\boldsymbol{C}-\boldsymbol{E}$, $100 \mu \mathrm{m} . \boldsymbol{F}$, The percentages of rabies-labeled cells in each layer of $\mathrm{V} 1 \mathrm{for}$ a single region from JNM1 (blue squares) and three separate regions from JNM10R (black, green, red squares). The averaged values across all quantified regions and cases (gray bars) were derived from a total of 15,013 labeled cells.

identified visual areas known to have monosynaptic connections with MT, including V1, V2, and V3 (Maunsell and van Essen, 1983). Within these areas substantial label was present in the layers known to connect monosynaptically with MT (Maunsell and van Essen, 1983) in addition to label outside of those layers that must consist of cells disynaptic to MT. Although extensive label was found in multiple visual areas, it is unlikely, based on the known cortical circuitry and our $3 \mathrm{~d}$ survival time, that rabies virus transported through one of these areas and into V1 (but see Discussion). Most importantly, any label in layer 4C of V1 absolutely must be disynaptic to MT-projecting V1 cells. This must be the case, because layer $4 \mathrm{C}$ neurons do not project axons out of $\mathrm{V} 1$ and could be labeled only by local connections to neurons within V1 that project to MT.

We found extensive label in V1 from both cases. In one case 
(JNM1) all of the label in V1 was confined to the calcarine sulcus (Fig. 1C), and in the other case (JNM10R) label was found primarily on the opercular surface (Fig. $1 D$ ). We counted cells in 12 sections from four separate regions of label, one from case JNM1 and three from case JNM10R. These were regions in which we found disynaptic label to be densest (see Materials and Methods). The laminar distribution of cell label was calculated for each region and subsequently averaged across regions and cases (Fig. $1 F)$. As expected, labeled cells were found in large numbers in layers 4B (25\%) and $6(17 \%)$, layers of V1 known to project directly to MT (Fig. 1C-F). Labeled cells in these layers likely consisted of cells both monosynaptic and disynaptic to MT. We also observed label outside of these layers, which must be cells disynaptic to MT. Disynaptic label was found in layer 2/3 (12\%), which likely connects to MT through both layers 4B and 6 (Fig. $1 C-F)$. The label in layer $2 / 3$ did not show any clear bias toward the blob or interblob regions, yet no quantitative analysis was used. Most interestingly, however, was the large number of cells disynaptic to MT found in layer $4 \mathrm{C}$ of $\mathrm{V} 1$. These cells were present almost exclusively in M-dominated layer $4 \mathrm{C} \alpha(40 \%)$ and rarely in P-dominated layer $4 \mathrm{C} \beta(1 \%)$ (Fig. $1 C-F)$. Averaged across cases, $97 \%$ of disynaptic label in layer $4 \mathrm{C}$ of $\mathrm{V} 1$ was found in layer $4 \mathrm{C} \alpha$. Although there was clear variability across regions and cases in the percentages of labeled cells within each layer (Fig. $1 F$ ), the relative absence of labeled cells in layer $4 \mathrm{C} \beta$ as compared with layer $4 \mathrm{C} \alpha$ was clear and showed little variability. Furthermore, labeled cells within layer $4 \mathrm{C} \beta$ tended to be near the $4 \mathrm{C} \alpha$ / $4 \mathrm{C} \beta$ border, raising the possibility that they could receive M LGN input via dendrites extending into $4 \mathrm{C} \alpha$ (Yabuta and Callaway, 1998). These results indicate that cells projecting directly from V1 to $\mathrm{MT}$ receive input almost exclusively from $\mathrm{M}$-dominated layer $4 \mathrm{C} \alpha$ and rarely from $\mathrm{P}$-dominated layer $4 \mathrm{C} \beta$.

Although disynaptic input from layer $4 \mathrm{C}$ of V1 to MT originates almost exclusively in M-dominated layer $4 \mathrm{C} \alpha$, MT nevertheless may receive substantial input from P-dominated layer $4 \mathrm{C} \beta$. Such a pathway simply may require additional synaptic relays either within V1 or through areas V2 or V3 before reaching MT. To test whether MT indeed receives input from P-dominated layer $4 \mathrm{C} \beta$, we made injections targeted to MT of one macaque monkey, in this case with a $6 \mathrm{~d}$ survival time, allowing rabies virus to transport up to four synapses past the cells that project directly to MT. The locations of the unilateral injections were confirmed histologically to be confined to MT (Fig. 2A). The needle penetration can be seen within the region of dense and uniform myelination along the posterior bank of the STS (Fig. $2 A)$. The resulting transsynaptic label in V1 showed distinctive laminar patterns depending on the topographic location analyzed within V1 (Figs. 2, 3). In the densest, most central region of label, in this case extending $\sim 2 \mathrm{~cm}$ mediolaterally and throughout the entire anterior-posterior extent of the calcarine sulcus, label was found extensively throughout every layer of V1 (Fig. $2 B, C)$. Particularly large numbers of rabies-labeled cells were found in layers $2 / 3(39 \%), 4 \mathrm{~B}(13 \%), 4 \mathrm{C} \alpha(18 \%)$, and $4 \mathrm{C} \beta$ (15\%). Importantly, $46 \%$ of transsynaptic label in layer $4 \mathrm{C}$ of $\mathrm{V} 1$ was found in layer $4 \mathrm{C} \beta$. Label in this region of $\mathrm{V} 1$ most likely corresponds to the locations of V1 cells projecting directly to the rabies-injected site in MT and transsynaptic spread predominantly across the local circuits of V1, but also through V2 and V3, up to four synapses past the directly infected cells.

As we analyzed areas of $\mathrm{V} 1$ outside of this central region of dense labeling, particularly $6 \mathrm{~mm}$ medial from center where the calcarine sulcus joins the opercular surface and extending onto the opercular surface as far as $10 \mathrm{~mm}$ laterally and just $10 \mathrm{~mm}$

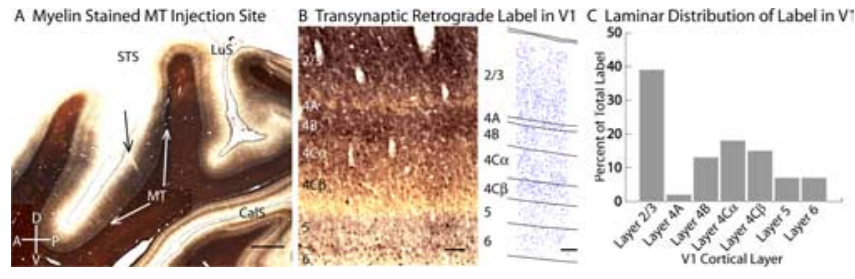

Figure 2. Retrogradely labeled neurons in $\mathrm{V} 1$ after a $6 \mathrm{~d}$ survival injection of rabies virus in cortical area MT. A, A montage of digitally photographed images of a single parasagittally cut cortical section stained for myelin showing the location of the rabies-injected region (black arrow) in the uniformly dense myelination of area MT (white arrows) along the posterior bank of the STS. LuS, Lunate sulcus; CalS, calcarine sulcus. Scale bar, $2 \mathrm{~mm}$. D, Dorsal; V, ventral; P, posterior; $A$, anterior. $\boldsymbol{B}$, Left, Parasagittally cut cortical section stained for the nucleocapsid protein of the rabies virus (black) and for $\mathrm{CO}$ (brown) through the central, densest region of label in V1 after a $6 \mathrm{~d}$ survival time. The bottom of the image is cropped at the layer 6/white matter border. $\boldsymbol{B}$, Right, Computer-assisted reconstruction of rabies-labeled cells (blue dots) in an adjacent parasagittally cut cortical section in the calcarine sulcus of V1. Cortical layers are indicated. Scale bars, $\boldsymbol{A}, \boldsymbol{B}, 100 \mu \mathrm{m}$. $\boldsymbol{C}$, The percentages of rabies-labeled cells in each layer of V1 within the central, densest region of transsynaptic label in the calcarine sulcus. The values (gray bars) for this particular region were derived from a total of 2017 labeled cells.

posterior to the V1/V2 border, we noticed that the laminar patterns of label changed and that labeled cells quickly decreased in density. Along the opercular surface, $\sim 16 \mathrm{~mm}$ from center, we found dense labeling in layers $4 \mathrm{~B}(21 \%), 4 \mathrm{C} \alpha(29 \%)$, and $6(22 \%)$ along with less but still substantial label in layers $2 / 3(11 \%), 4 \mathrm{C} \beta$ (7\%), and 5 (7\%) (Fig. $3 A, B$ ). Just $2 \mathrm{~mm}$ anterior to this location, $\sim 18 \mathrm{~mm}$ from center, the laminar distribution of cell label was similar to that after injections into MT with a $3 \mathrm{~d}$ survival, with the majority of cells in layers 4B (13\%), 4C $\alpha(24 \%)$ and $6(42 \%)$ (Fig. $3 C, D$ ). Only $2 \%$ of the cell label was found in layer $4 \mathrm{C} \beta$, with $94 \%$ of layer $4 \mathrm{C}$ cell label confined to layer $4 \mathrm{C} \alpha$. Finally, farthest away from center, labeled cells were found only in layers known to connect monosynaptically with MT, layers $4 \mathrm{~B}$ and 6 . We suggest that these varying patterns of label likely reflect transsynaptic horizontal spread of rabies virus, primarily within layers $4 \mathrm{~B}$ and 6 of $\mathrm{V} 1$, followed by vertical spread to other layers (Fig. $3 E, F$ ). Additionally, transsynaptic spread within MT and through V2 and V3 likely contributes to the pattern of label observed in V1. This suggests that, as one moves closer to the center of label, the laminar pattern reflects spread across progressively more synapses involving vertical connections. Most importantly, however, was that in the densest regions we found extensive label in layer $4 \mathrm{C} \beta$ (Figs. $2 B, C, 3 E$ ). Within five synapses, MT received substantial input from $\mathrm{P}$-dominated layer $4 \mathrm{C} \beta$.

Although our $6 \mathrm{~d}$ survival MT injection provided clear evidence for a multisynaptic input from $\mathrm{P}$-dominated layer $4 \mathrm{C} \beta$ to $\mathrm{MT}$, the route by which this $\mathrm{P}$ pathway input arrives into MT remained unclear. The labeled cells observed in $\mathrm{P}$-dominated layer $4 \mathrm{C} \beta$ could reach MT by many hypothesized pathways, the most plausible being via MT-projecting cells in V1, V2, and/or V3. Because V1 projects indirectly to MT through V3 and the CO thick stripes of V2 (Maunsell and van Essen, 1983; Shipp and Zeki, 1989b), we made injections of rabies virus into these two extrastriate cortical areas. Although it is known that $\mathrm{V} 2$ receives a strong input from the $\mathrm{P}$ pathway via layer $2 / 3$ cells in $\mathrm{V} 1$, this pathway requires at least two synapses between layer $4 \mathrm{C} \beta$ and the layer 2/3 output cells (Sawatari and Callaway, 2000). Only layer $4 \mathrm{~B}$ pyramidal cells in $\mathrm{V} 1$ both project to $\mathrm{V} 2$ and receive direct input from layer $4 \mathrm{C} \beta$; thus we did not expect to observe any disynaptic label in layer $4 \mathrm{C} \beta$ unless our injections targeted the axons of large numbers of layer $4 \mathrm{~B}$ cells. Because of the robust projection from layer 4B of V1 to V3 (Burkhalter et al., 1986), as well as the more 

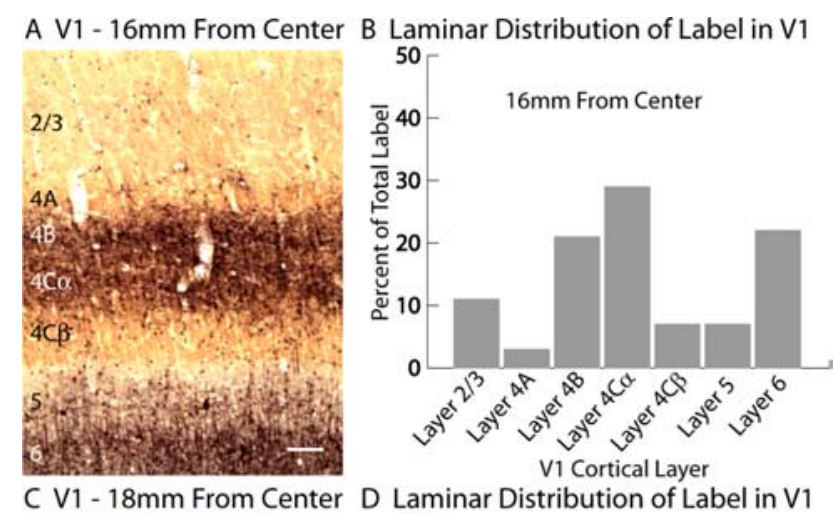

\section{Laminar Distribution of Label in V1}

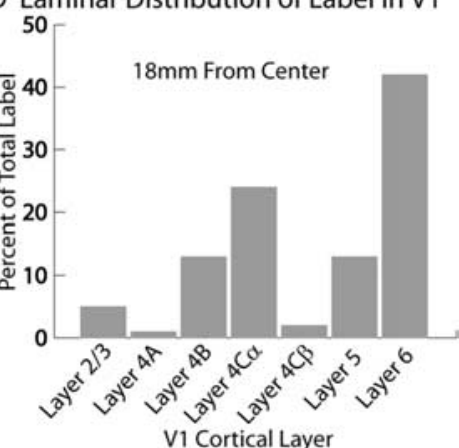

F Topographic Virus Transport -6 days

E V1 Topographic Pattern
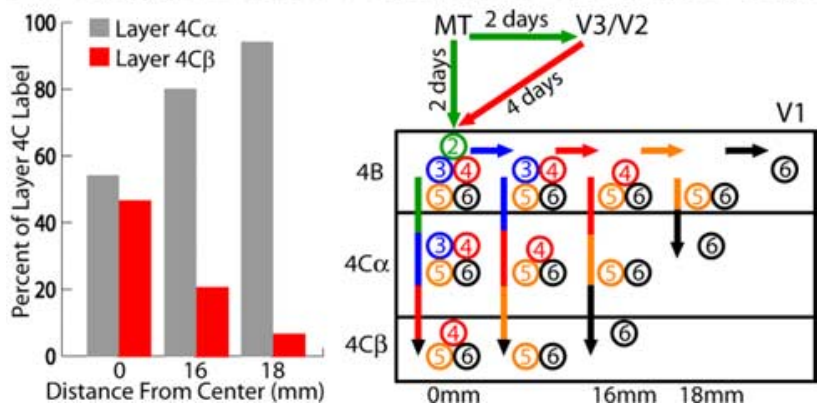

Figure 3. Transsynaptic spread of rabies-labeled cells in $\mathrm{V} 1$ after a $6 \mathrm{~d}$ survival injection of rabies virus in cortical area MT. $A, C$, Parasagittally cut cortical sections of V1 from case JNM11 stained for the nucleocapsid protein of the rabies virus (black) and for $\mathrm{CO}$ (brown). Outside of the central, densest regions of label in the calcarine sulcus of V1, the laminar profile of labeled cells changed considerably. A reduced density of label across layers and fewer numbers of cells located outside of layers $4 B, 4 C \alpha$, and 6 were observed $\sim 16 \mathrm{~mm}$ away from center $(A)$. This reduction in cell density was even more prevalent $18 \mathrm{~mm}$ from center (C). Approximately $10 \%$ of layer 6 is cropped at the bottom of each image. Cortical layers are indicated. Scale bars: $A, C$, $100 \mu \mathrm{m}$. The percentages of rabies-labeled cells in each layer of $\mathrm{V} 1$ for regions $\sim 16 \mathrm{~mm}(\boldsymbol{B})$ and $18 \mathrm{~mm}(\boldsymbol{D})$ away from the center of densest transsynaptic label are indicated. The values (gray bars) for these regions were derived from a total of 659 and 1804 labeled cells, respectively. $\boldsymbol{E}$, Percentages of rabies-labeled cells in layer $4 C \alpha$ (gray bars) versus layer $4 C \beta$ (red bars) of $\mathrm{V} 1$ within the central, densest region of label in the calcarine sulcus as well as regions $\sim 16$ and 18 $\mathrm{mm}$ from center. The proportion of transsynaptic label in layer $4 C \beta$ gradually decreased at topographic regions farther away from the central region of label. $\boldsymbol{F}$, Schematic of potential transsynaptic retrograde viral transport from MT back to $\mathrm{V} 1$, based on a $6 \mathrm{~d}$ survival time and the known cortical circuitry within and among V1, V2, V3, and MT. Colored, circled numbers indicate the minimum number of days required for retrograde transport to reach that topographic and laminar location. Within a $6 \mathrm{~d}$ survival time the rabies virus had time to spread four synapses past the cells in V1 that project directly to MT, most likely spreading along the long-distance horizontal connections within layers $4 B$ and 6 of $\mathrm{V} 1$, followed by vertical spread within local columnar circuits to other layers. Rabies virus also had time to spread two synapses past the cells in V1 projecting indirectly to MT through V2 and V3.

balanced incidence of both color-selective and direction-selective neurons in V3 as compared with MT (Felleman and Van Essen, 1987; Gegenfurtner et al., 1997), a higher proportion of disynaptic label in P-dominated layer $4 \mathrm{C} \beta$ was expected.

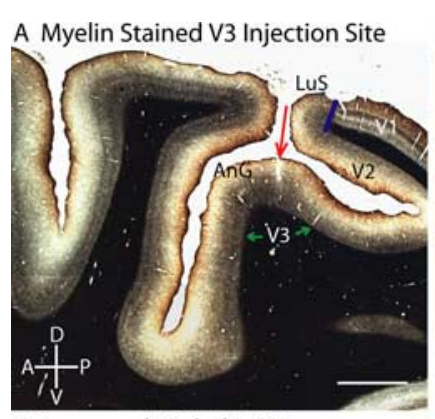

B Rabies Stained V3 Injection Site

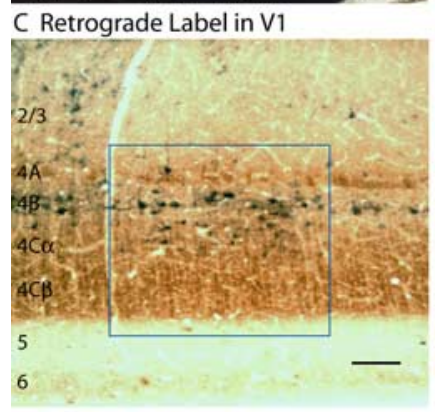

E Cell Count Reconstruction in V1

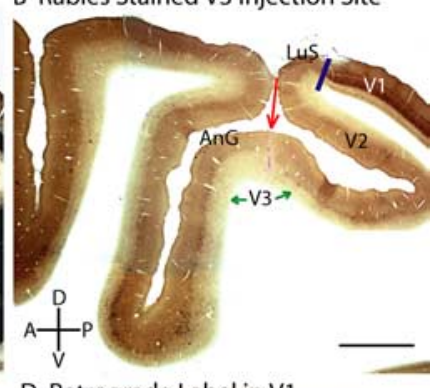

D Retrograde Label in V1
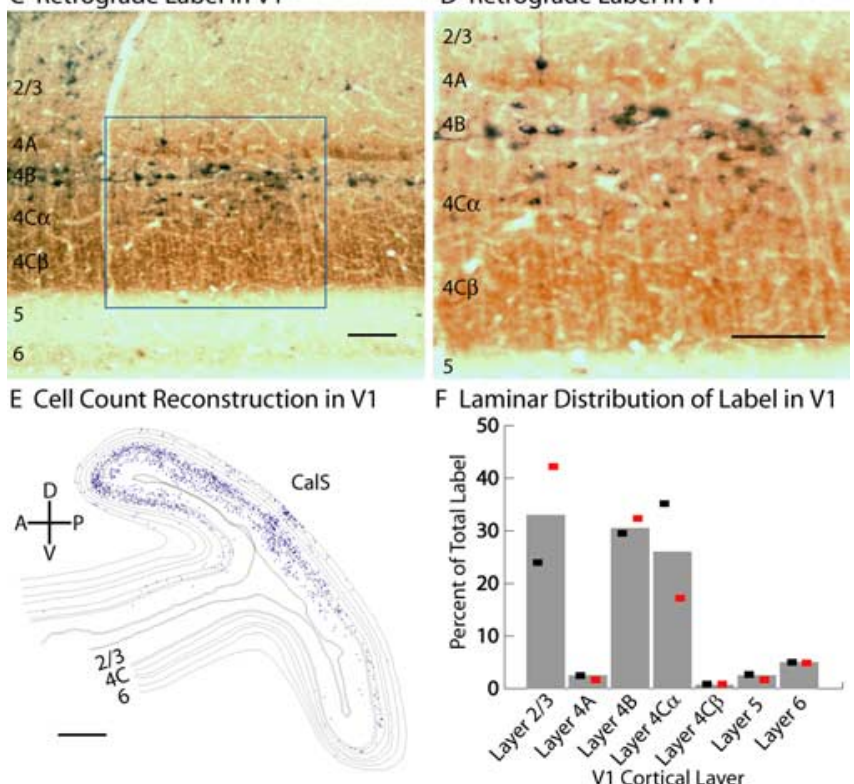

F Laminar Distribution of Label in V1

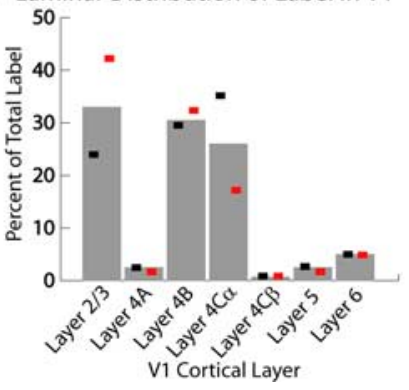

Figure 4. Retrogradely labeled neurons in V1 after injections of rabies virus in cortical area V3. A, A montage of digitally photographed images of a single parasagittally cut cortical section stained for myelin showing the location of the rabies-injected region (red arrow) in the uniformly dense myelination of area V3 (green arrows) along the annectent gyrus (AnG), buried in the lunate sulcus (LuS) $\sim 12 \mathrm{~mm}$ anterior to the V1/V2 border (blue line). $\boldsymbol{B}, \mathrm{A}$ montage of digitally photographed images of an adjacent parasagittal cortical section to that in $\boldsymbol{A}$ stained for the nucleocapsid protein of the rabies virus (black) and for CO (brown). D, Dorsal; $V$, ventral; P, posterior; A, anterior. Scale bars: $\boldsymbol{A}, \boldsymbol{B}, 2 \mathrm{~mm}$. $\boldsymbol{C}$, Parasagittally cut cortical section of V1 from case JNM4 stained for the nucleocapsid protein of the rabies virus (black) and for CO (brown). The bottom of the image is cropped at the layer 6/white matter border. Cortical layers are indicated. $\boldsymbol{D}$, Higher magnification image of the location indicated by the blue rectangle in $\boldsymbol{C}$ showing the presence of rabies-labeled cells in layers $4 B$ and $4 C \alpha$ of $\mathrm{V} 1$, but not $4 C \beta$. Scale bars: $\boldsymbol{C}, \boldsymbol{D}, 100 \mu \mathrm{m}$. $\boldsymbol{E}$, Computer-assisted reconstruction of rabies-labeled cells (blue dots) in a single parasagittally cut cortical section through a dense region of label in the calcarine sulcus (CaIS) of V1. Scale bar, $1 \mathrm{~mm}$. F, The percentages of rabies-labeled cells in each layer of V1 for JNM3 (black squares) and JNM4 (red squares). The averaged values across both cases (gray bars) were derived from a total of 8515 labeled cells.

Injections of rabies virus were targeted to dorsal V3 of two macaque monkeys with a $3 \mathrm{~d}$ survival time. The locations of the unilateral injections were confirmed histologically to be confined to V3 (Fig. 4A, B). The needle penetration can be seen within the region of dense and uniform myelination along the annectent gyrus, within the lunate sulcus, $\sim 12 \mathrm{~mm}$ anterior to the V1/V2 border (Fig. 4A); in an adjacent $\mathrm{CO}$ and rabies-stained section the labeling is less dense at the injection site and more dense in the surrounding cortex (Fig. $4 \mathrm{~B}$ ). The absence of strong labeling in the immediate vicinity of the virus injection was typical in our studies and was expected because of mechanisms of rabies virus uptake and similar descriptions of injection site labeling from previous studies (Kelly and Strick, 2000). The resulting label in 
V1 of both cases was located mostly along the dorsal one-half of the calcarine sulcus, showing a very similar topographic pattern to that shown previously after injections of monosynaptic retrograde tracers into V3 (Fig. 4E) (Burkhalter et al., 1986). We counted cells in a total of six sections, three from each of two different cases, in regions in which we found disynaptic label to be densest (Fig. $4 E$ ) and calculated the resulting laminar distribution of cell label (Fig. $4 F$ ). As expected, label was found in large numbers in layer $4 \mathrm{~B}(31 \%)$, the only layer of $\mathrm{V} 1$ known to project directly to V3 (but see Felleman et al., 1997) (Fig. 4C-F). Labeled cells in this layer probably consisted of cells both monosynaptic and disynaptic to V3. We also observed label outside of this layer, which includes cells disynaptic to V3. Label was found in large quantities in layer 2/3 (33\%) (Fig. 4C-F) and did not show any clear bias toward the blob or interblob regions, yet no quantitative analysis was used. Large numbers of cells disynaptic to V3 were found in layer $4 \mathrm{C}$ of V1. Surprisingly, these cells were present almost exclusively in M-dominated layer $4 \mathrm{C} \alpha(26 \%)$ and rarely in $\mathrm{P}$-dominated layer $4 \mathrm{C} \beta(1 \%)$ (Fig. $4 C-F)$. Averaged across cases, $98 \%$ of disynaptic label in layer $4 \mathrm{C}$ of $\mathrm{V} 1$ was found in layer $4 \mathrm{C} \alpha$. Again, although there was clear variability across regions and cases in the percentages of labeled cells within each layer (Fig. $4 F$ ), the relative absence of label in layer $4 \mathrm{C} \beta$ as compared with layer $4 \mathrm{C} \alpha$ was clear and showed little variability. These results indicate that cells projecting directly from $\mathrm{V} 1$ to $\mathrm{V} 3$ receive input almost exclusively from $\mathrm{M}$-dominated layer $4 \mathrm{C} \alpha$ and rarely from $\mathrm{P}$-dominated layer $4 \mathrm{C} \beta$.

Although we found little evidence for disynaptic input from $\mathrm{P}$-dominated layer $4 \mathrm{C} \beta$ to MT or V3, the P pathway still could connect indirectly with MT through the CO thick stripes of V2 (Yabuta et al., 2001; Born and Bradley, 2005). It long had been thought that layer $2 / 3$ blobs, layer $2 / 3$ interblobs, and layer $4 \mathrm{~B}$ of V1 connected specifically to V2 thin stripes, pale stripes, and thick stripes, respectively (Livingstone and Hubel, 1988). Recent evidence, however, suggests that there is not such a clean one-toone correspondence between V1 and V2 compartments (Sincich and Horton, 2002; Xiao and Felleman, 2004), making it even less clear what the relative contributions of $\mathrm{M}$ and $\mathrm{P}$ pathways might be to any given V2 stripe type.

Injections of rabies virus were targeted to V2 of two macaque monkeys with a $3 \mathrm{~d}$ survival time, just posterior to the lunate sulcus along the opercular surface. Multiple injections were made unilaterally for each animal (additional details below), and their locations were confirmed histologically to be confined to V2 (Fig. $5 A$ ). The pipette penetration for one of the injections can be seen $\sim 1 \mathrm{~mm}$ anterior to the V1/V2 border along the opercular surface and, importantly, an absence of label can be seen posterior to the injection site within close proximity to the V1/V2 border (Fig. $5 A$ ). The lack of label closely surrounding the V1/V2 border made us confident that the observed retrograde label in V1 was not the result of a large injection that spread across the V1/V2 border. We were not able to evaluate directly whether any of the V2 injections were confined to a particular CO stripe type, because we chose to section our tissue across layers to reveal clearly the laminar borders and depth in V1.

In case JNM13 10 injections were made in close proximity to each other, resulting in overlapping foci of retrograde label in V1. In case JNM10L, however, seven injections were made with greater separation between injection sites, resulting in foci of retrograde label in V1 that could be analyzed independently of one another. Although the resulting label in V1 after injections from the latter case could not be attributed with certainty to an individual thick, thin, or pale stripe, we did see systematic varia- tion in the pattern of V1 label resulting from one injection site to another. Based on the known pattern of monosynaptic connections between V1 and particular stripe types in V2 (Livingstone and Hubel, 1987, 1988; Sincich and Horton, 2002; Sincich et al., 2006), as well as local V1 connections (Callaway, 1998, 2005), inferences as to the single stripe type or multiple stripe types involved in a particular injection site sometimes could be made and will be discussed additionally below. The resulting label in V1 was always found a certain distance posterior to the V1/V2 border that corresponded well retinotopically with the location of the injections into V2.

The overall laminar patterns of label in V1 varied between V2 injections, depending on the patterns of label in blobs versus interblobs of layer $2 / 3$ as well as layer $4 \mathrm{~B}$. This suggested a dependence on injection location relative to V2 stripe compartments. First we describe foci with strong label in all three V1 compartments that project to V2 (blobs, interblobs, and layer 4B), likely the result of injections involving all three V2 stripe types (see below). We counted cells in 12 sections from four separate foci of label, two from case JNM10L and two from case JNM13, where we found disynaptic label to be densest. These four foci were distinguishable from the others based on the indiscriminate pattern of cells in layer $2 / 3$ in relation to the blob and interblob regions (Fig. $5 B$ ). Overall, label was found in greatest proportion in layer $2 / 3$ (30\%) of V1, which is known to provide heavy, direct input primarily to the thin and pale stripes of V2 (Figs. $5 B, 6 B$ ) (Livingstone and Hubel, 1988; Sincich and Horton, 2002; Sincich et al., 2006). The labeled cells in layer $2 / 3$ did not show any clear bias toward the blob or interblob regions and presumably included cells both monosynaptic and disynaptic to V2. Substantial label, however, also was found in nearly every other layer. Earlier work has shown that all layers of V1 outside of layer 4C may connect monosynaptically with V2 (Kennedy and Bullier, 1985; Livingstone and Hubel, 1988; Rockland, 1992; Sincich and Horton, 2002) and that all of these layers also can provide local input to each other (Callaway, 1998). It is, therefore, unclear which label outside of layer $4 \mathrm{C}$ is monosynaptic versus disynaptic. Importantly, however, any label within layer $4 \mathrm{C}$ was certainly disynaptic to V2. Substantial label was found in layer 4B (14\%) of V1, which is known to provide direct input primarily to the thick stripes of V2 (Figs. 5B, 6A,B). Additionally, label was found in layers $5(7 \%)$ and $6(22 \%)$ (Fig. 6B). Interestingly, however, in these selected foci of label we found disynaptic label in layer $4 \mathrm{C}$ of $\mathrm{V} 1$ to be much more balanced between $4 \mathrm{C} \alpha$ and $4 \mathrm{C} \beta$ as compared with injections into MT or V3. Labeled cells were found in both M-dominated layer $4 \mathrm{C} \alpha(19 \%)$ and $\mathrm{P}$-dominated layer $4 \mathrm{C} \beta$ $(6 \%)$ (Fig. 6A, B). Averaged across cases, $23 \%$ of disynaptic label in layer $4 \mathrm{C}$ of $\mathrm{V} 1$ was found in layer $4 \mathrm{C} \beta$. Labeled cells in layer $4 \mathrm{C} \beta$ were found from the upper border with layer $4 \mathrm{C} \alpha$ to the lower border with layer 5 , showing a strikingly different distribution and prevalence than after injections into MT or V3. These results indicate that the group of cells projecting directly from $\mathrm{V} 1$ to the V2 compartments injected in these cases collectively receives mixed input from both $\mathrm{M}$-dominated layer $4 \mathrm{C} \alpha$ and P-dominated layer $4 \mathrm{C} \beta$.

As was noted earlier, however, some injections into V2 of case JNM10L resulted in differing patterns of label in V1. Two foci of label showed a pattern in which layer $2 / 3$ cells were found primarily in the blob regions (Fig. $5 C$ ), likely the result of injections localized to a thin stripe (see below), and one focus of label showed a pattern in which cells extended more superficially within the blob regions of layer $2 / 3$ than in other foci (Fig. $5 D$ ). We counted cells in six sections from two separate foci of label, 


\section{A V2 Injection Site}

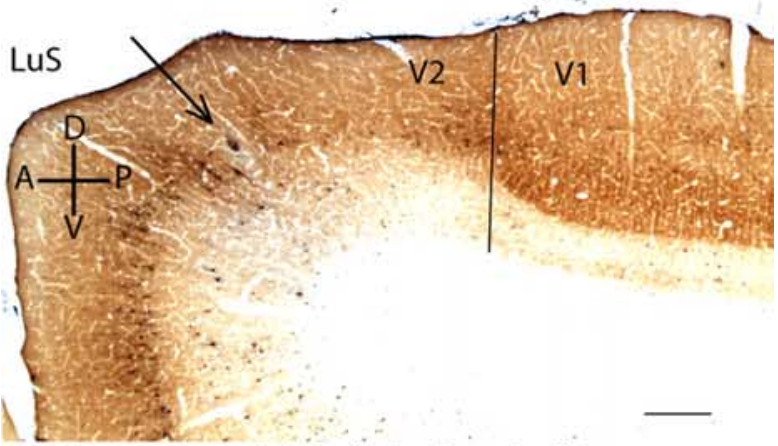

B Blob \& Interblob Labeling in V1

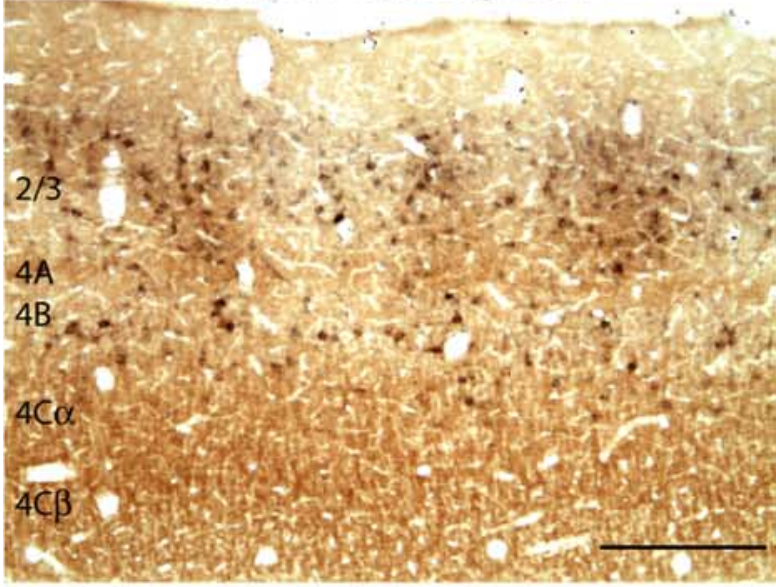

\section{Blob Biased Labeling in V1}

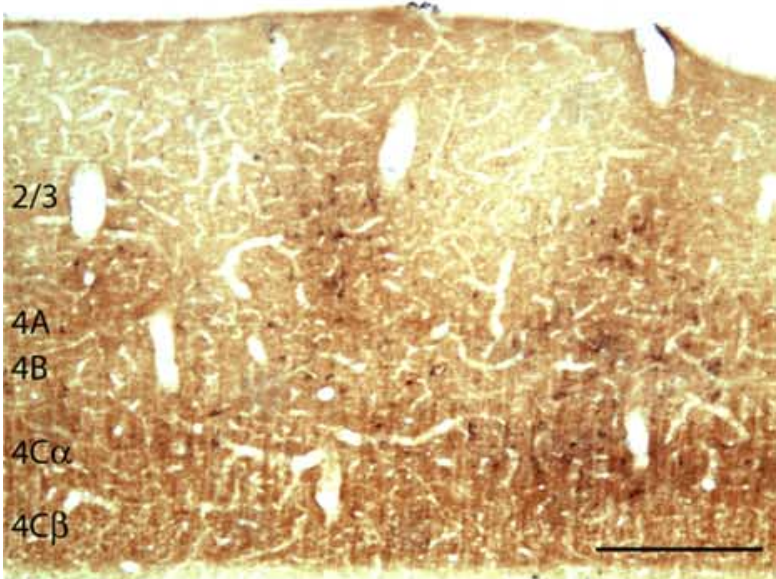

\section{Upper Layer 2 Blob Labeling in V1}

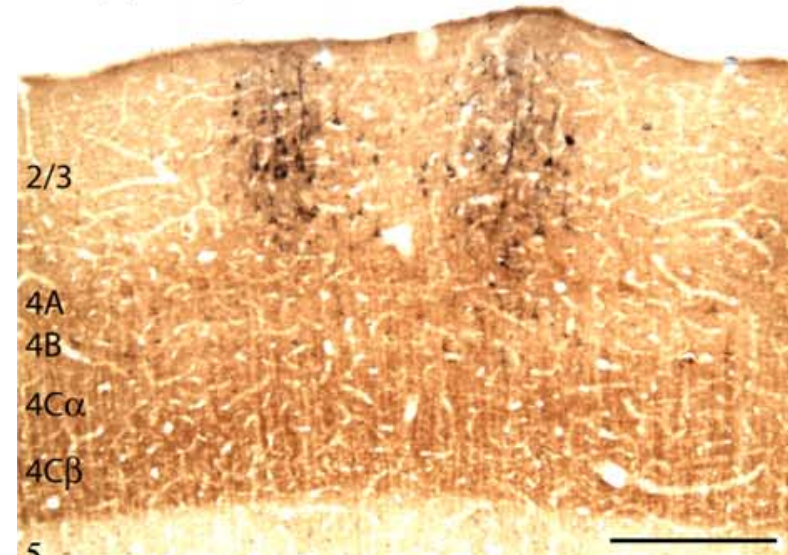

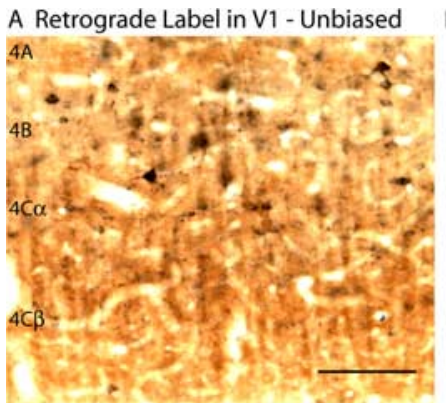

B Laminar Distribution of Label in V1

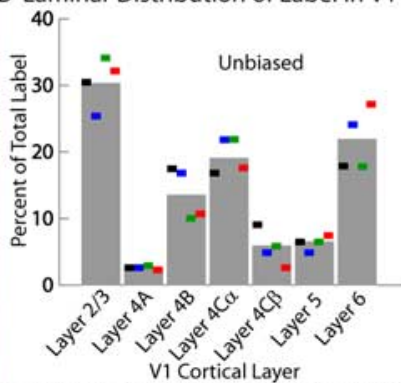

C Retrograde Label in V1 - Blob Biased D Laminar Distribution of Label in V1
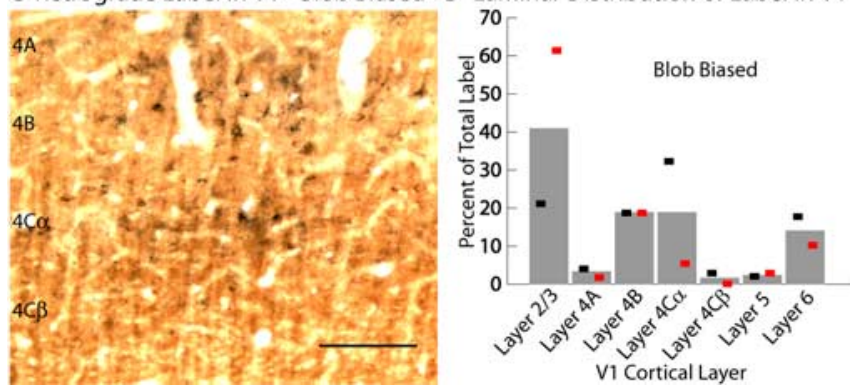

Figure 6. Laminar distribution of rabies-labeled cells in $\mathrm{V} 1$ after injections of rabies virus in cortical area V2. A, C, Parasagittally cut cortical sections of V1 (JNM10L) from a blob-unbiased $(\boldsymbol{A})$ and blob-biased $(\boldsymbol{C})$ pattern of label stained for the nucleocapsid protein of the rabies virus (black) and for CO (brown). Cortical layers are indicated. Scale bars: $\boldsymbol{A}, \boldsymbol{C}, 100 \mu \mathrm{m}$. B, The percentages of rabies-labeled cells in each layer of V1 for case JNM13 (green and red squares) and JNM10L (black and blue squares) from foci with blob-unbiased patterns of label. $\boldsymbol{D}$, The percentages of rabies-labeled cells in each layer of V1 for case JNM10L from two separate foci (black and red squares) with blob-biased patterns of label. The averaged values across all quantified foci and cases (gray bars) for blob-unbiased $(\boldsymbol{B})$ and blob-biased $(\boldsymbol{D})$ patterns of label were derived from a total of 25,071 and 1811 labeled cells, respectively.

both from case JNM10L, in which the pattern of label in layer $2 / 3$ showed a clear bias toward the blob regions (Fig. 5C). In these foci labeling again was found in high proportion in layers $2 / 3(41 \%)$, 4B (19\%), and $6(14 \%)$ (Figs. 5C, 6D). Although there was substantial variability in the proportion of cell label in these layers, disynaptic label was consistently absent from layer 4C $\beta$. Cells disynaptic to V2 in layer 4C of V1 were found almost exclusively in $\mathrm{M}$-dominated layer $4 \mathrm{C} \alpha(19 \%)$ and rarely in P-dominated layer $4 \mathrm{C} \beta$ (2\%) (Fig. 6C,D). Averaged across the two cases, 95\% of disynaptic label in layer $4 \mathrm{C}$ of $\mathrm{V} 1$ was found in layer $4 \mathrm{C} \alpha$. These results indicate that cells projecting directly from V1 to the V2 compartments injected in these cases receive direct input almost exclusively from M-dominated layer $4 \mathrm{C} \alpha$ and rarely from P-dominated layer $4 \mathrm{C} \beta$.

Although we could not localize our V2 injections to any particular stripe type, we believe that any substantial disynaptic label in layer $4 \mathrm{C} \beta$ was likely the result of injections involving a thick stripe (Fig. $7 B$ ). We recognize that this inference is likely to be contrary to the preconceived notions of many readers; however,

Figure 5. Retrogradely labeled neurons in V1 after injections of rabies virus in cortical area V2. A, A single parasagittally cut cortical section stained for the nucleocapsid protein of the rabies virus (black) and for $\mathrm{CO}$ (brown) showing the location of the rabies-injected region (black arrow) $\sim 1 \mathrm{~mm}$ anterior to the V1/V2 border (black line) just posterior to the lunate sulcus (LuS). $D$, Dorsal; $V$, ventral; $P$, posterior; $A$, anterior. $\boldsymbol{B}-\boldsymbol{D}$, Parasagittally cut cortical sections of $\mathrm{V} 1$ from case JNM10L stained for the nucleocapsid protein of the rabies virus (black) and for $\mathrm{CO}$ (brown). Multiple patterns of retrograde label were observed in $\mathrm{V} 1$, including labeling with relatively unbiased scatter in both $\mathrm{C} 0$ blobs and interblobs of layer $2 / 3(\boldsymbol{B})$, labeling biased to the $\mathrm{C} 0$ blobs in layer $2 / 3(C)$, and labeling biased to the $C 0$ blobs of layer $2 / 3$ and extending superficially to the top of layer 2 (D). Cortical layers are indicated. Scale bars, $250 \mu \mathrm{m}$. 


\section{A Disynaptic Layer 4C Label}

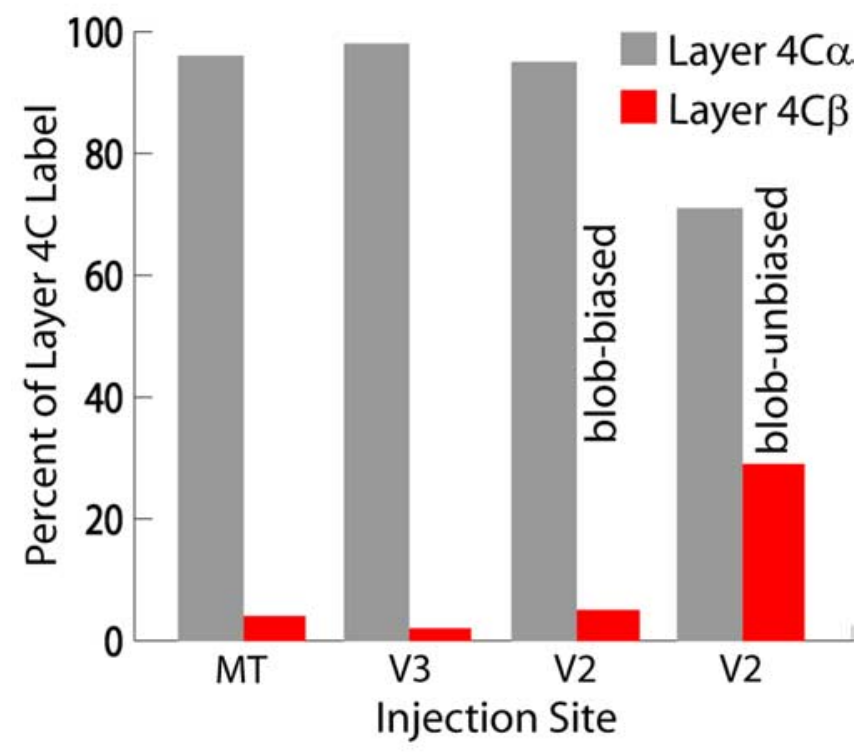

\section{B Potential V1-V2 Virus Transport}

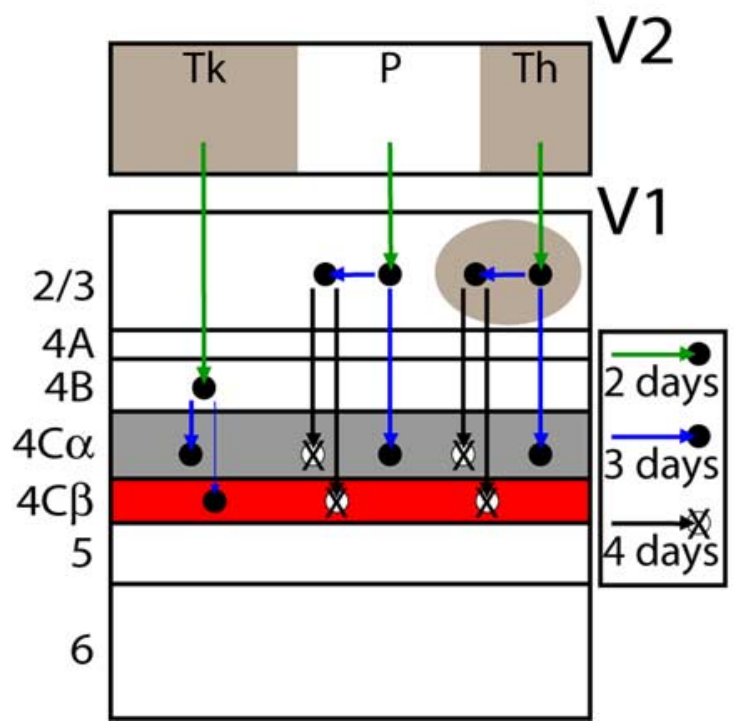

Figure 7. Cortical circuitry underlying varying patterns of retrograde label in layer $4 \mathrm{C}$ of $\mathrm{V} 1$. $A$, Percentages of rabies-labeled cells in layer $4 C \alpha$ (gray bars) versus layer $4 C \beta$ (red bars) of $\mathrm{V} 1$ resulting from injections of rabies virus into MT, V3, or V2. Values were averaged across all quantified regions and cases for each cortical area that was injected. Only particular injections into $\mathrm{V} 2$, in which layer $2 / 3$ label was relatively unbiased toward blobs versus interblobs, resulted in substantial disynaptic label in layer $4 C \beta . B$, Schematic of potential retrograde viral transport from V2 back to V1 based on known cortical circuitry between the two visual areas, photostimulation data (Sawatari and Callaway, 2000), and the $3 \mathrm{~d}$ survival time in our experiments. Layer 3 projection neurons within V1 receive input from layer $4 C \alpha$, but not layer $4 C \beta$, making pale (P) and thin (Th) stripes of $\mathrm{V} 2$ unlikely sources of the observed disynaptic label in layer $4 C \beta$. Layer $4 \mathrm{~B}$ projection neurons in $\mathrm{V} 1$, however, receive input from both layers $4 \mathrm{C} \alpha$ and $4 C \beta$, making thick (Tk) stripes the more likely source of the observed disynaptic label in layer $4 C \beta$.

it is supported strongly by the evidence we describe below. Previous studies that used photostimulation showed that layer 3 cells projecting outside of $\mathrm{V} 1$ receive input from layer $4 \mathrm{C} \alpha$, but not layer $4 \mathrm{C} \beta$; only layer 3 cells with exclusively local projections receive layer $4 \mathrm{C} \beta$ input (Sawatari and Callaway, 2000). Any layer $4 \mathrm{C} \beta$ contribution relayed from layer 3 to V2 must be trisynaptic (Lachica et al., 1992; Yabuta et al., 2001). Therefore, thin and pale stripes of $\mathrm{V} 2$, which receive the bulk of their input from layer 3 cells in the blob and interblob regions, respectively (Livingstone and Hubel, 1988; Rockland, 1992; Sincich and Horton, 2002; Sincich et al., 2006), are not likely to be the source of the observed disynaptic label in layer $4 \mathrm{C} \beta$ (Fig. $7 B$ ). Consistent with this interpretation, injections into $\mathrm{V} 2$ that resulted in retrograde V1 label primarily in the blobs of layer $2 / 3$ (likely because of thin stripe injections) resulted in substantial disynaptic label in layer $4 \mathrm{C} \alpha$, but not in layer $4 \mathrm{C} \beta$ (Fig. 7A). Only layer $4 \mathrm{~B}$ pyramidal and deep layer neurons in $\mathrm{V} 1$ both project to $\mathrm{V} 2$ and receive layer $4 \mathrm{C} \beta$ input (Briggs and Callaway, 2001, 2005; Yabuta et al., 2001). These are the only cells that could mediate disynaptic connections from layer $4 \mathrm{C} \beta$ to V2. Therefore, thick stripes of V2, which receive the bulk of their input from layer $4 \mathrm{~B}$ (Livingstone and Hubel, 1987) (but see Sincich and Horton, 2002), are the most likely source of the observed disynaptic label in layer $4 \mathrm{C} \beta$ (Fig. $7 B$ ). Consistent with this interpretation, only injections into V2 that resulted in retrograde label in both the blobs and interblobs of layer $2 / 3$ and in layer $4 \mathrm{~B}$ produced substantial disynaptic label in layer $4 \mathrm{C} \beta$ (Fig. $7 A$ ). These injections most likely involved V2 thick and/or pale stripes in addition to a thin stripe. Interestingly, we found that, after these injections into V2, 23\% of disynaptic label in layer $4 \mathrm{C}$ of $\mathrm{V} 1$ was confined to $\mathrm{P}$-dominated layer $4 \mathrm{C} \beta$. This corresponds well to previous photostimulation data showing that $30 \%$ of the layer $4 \mathrm{C}$ input to layer $4 \mathrm{~B}$ pyramidal cells comes from layer $4 \mathrm{C} \beta$ (Yabuta et al., 2001). This additionally supports our contention that the observed label in layer $4 \mathrm{C} \beta$ reaches V2 through layer $4 \mathrm{~B}$ pyramidal cells.

\section{Discussion}

Our observations demonstrate that the major ascending input through layer $4 \mathrm{C}$ of $\mathrm{V} 1$ to MT is dominated by the M pathway. The major input to $\mathrm{V} 3$ via layer $4 \mathrm{C}$ of $\mathrm{V} 1$ likewise is dominated by the $\mathrm{M}$ pathway. The $\mathrm{P}$ pathway nevertheless reaches MT indirectly, likely through the CO thick stripes of V2. After injections of rabies virus into MT ( $3 \mathrm{~d}$ survival) disynaptic label in layer $4 \mathrm{C}$ of $\mathrm{V} 1$ was found almost exclusively in M-dominated layer $4 \mathrm{C} \alpha$. Our $6 \mathrm{~d}$ survival MT injections, however, resulted in substantial transsynaptic label throughout all layers of V1, including $\mathrm{P}$-dominated layer $4 \mathrm{C} \beta$. The design of this experiment did not allow us to identify the particular route by which layer $4 \mathrm{C} \beta$ was labeled, but it provided conclusive evidence for a substantial indirect input from P-dominated layer $4 \mathrm{C} \beta$ of V1 to MT. In an attempt to elucidate the route by which this $\mathrm{P}$ pathway input reaches $\mathrm{MT}$, we made injections into areas V3 and V2. After injections of rabies virus into V3 (3 d survival), disynaptic label in layer 4C of V1 again was found almost exclusively in $\mathrm{M}$-dominated layer $4 \mathrm{C} \alpha$. Only after certain injections into V2, likely those that involved a thick stripe (see Results), was substantial disynaptic label found in $\mathrm{P}$-dominated layer $4 \mathrm{C} \beta$, making the thick stripes of V2 the most likely relay for $\mathrm{P}$ pathway input to MT.

The pattern of monosynaptic and disynaptic label in V1 was different in important ways after injections into MT, V3, and V2. It is important to note that some label outside of layer 4C, instead of being disynaptic to projection cells within V1, could be disynaptic to projection cells outside of $\mathrm{V} 1$, possibly labeled via ascending $\mathrm{V} 1$ axons that terminate outside of layer 4 in extrastriate cortex. The following analysis, however, is made with the assumption that the majority of label within V1 is either monosynaptic to the injection site or disynaptic to those same V1 projection cells. The most salient difference between the laminar profiles after injections into V3 versus MT was the higher pro- 
portion of label in layer $2 / 3$ and lower proportion of label in layer 6 after injections into V3 (Figs. $1 F, 4 F$ ). There is some indication from earlier work that layer $2 / 3$ of $\mathrm{V} 1$ may connect directly with V3 (Felleman et al., 1997), which would mean that the high proportion of label in layer $2 / 3$ consists of cells both monosynaptic and disynaptic to V3. The lower proportion of label in layer 6 of V1 was expected because, unlike MT, V3 does not receive monosynaptic connections from this layer (Burkhalter et al., 1986). Most striking, however, was the disproportionate amount of label in layer $4 \mathrm{C} \alpha$ as compared with layer $4 \mathrm{C} \beta$ after injections into either of these two visual areas (Fig. 7A). The relative absence of label in layer $4 \mathrm{C} \beta$ after injections into $\mathrm{V} 3$ was somewhat surprising given the preponderance of color selectivity found in this area (Felleman and Van Essen, 1987; Gegenfurtner et al., 1997) and the prevalence of connections between V3 and both MT and V4 (Felleman and Van Essen, 1991). There is some indication, however, that there is a modular organization to V3 similar to that of V2 (Lyon et al., 2002). Although unlikely, it remains possible that our injections into V3 involved only certain modules and that if all modules of $\mathrm{V} 3$ had been injected more substantial disynaptic label might have been observed in layer $4 \mathrm{C} \beta$. Nevertheless, our injections into both MT and V3 resulted in disynaptic label almost exclusively within the M-dominated sub layer of $4 \mathrm{C}$.

In contrast, after injections into $\mathrm{V} 2$, a more balanced proportion of label often was observed in layers $4 \mathrm{C} \alpha$ and $4 \mathrm{C} \beta$ (Fig. 7A), indicating mixed input from $\mathrm{M}$ and $\mathrm{P}$ pathways. Importantly, the prevalence of label in layer $4 \mathrm{C} \beta$ in these cases made it clear that the lack of label in layer $4 \mathrm{C} \beta$ after injections into MT and V3 was attributable to a weak or altogether nonexistent connection, eliminating the possibility that cells in layer $4 \mathrm{C} \beta$ are simply less vulnerable to rabies virus infection. Additionally, substantial amounts of label were found in every layer of $\mathrm{V} 1$ in these cases (Fig. 6B).

The laminar and columnar patterns of V1 label varied between V2 injections so that only some of our V2 injections resulted in substantial disynaptic label in P-dominated layer $4 \mathrm{C} \beta$ (Figs. 5, 6). Most of our injections into V2 resulted in retrograde label in V1 that was found indiscriminately in both blobs and interblobs of layer $2 / 3$, as well as layer $4 \mathrm{~B}$ (Fig. $5 B$ ). These injections most likely included all three stripe types in $\mathrm{V} 2$ and were the only injections that resulted in a substantial proportion of label in layer $4 \mathrm{C} \beta$ (Fig. $6 A, B$ ). Additionally, a few V2 injections resulted in retrograde label in $\mathrm{V} 1$ biased to the blobs of layer 2/3 (Fig. $5 C$ ). These injections most likely were isolated to a thin stripe in V2 and resulted in disynaptic label almost exclusively in layer $4 \mathrm{C} \alpha$ as compared with layer $4 \mathrm{C} \beta$ (Fig. $6 C, D$ ). Finally, one injection into $\mathrm{V} 2$ resulted in retrograde label in $\mathrm{V} 1$ biased to the blobs of layer $2 / 3$ and extending strikingly superficially to the top of layer 2 (Fig. $5 D)$. In this particular case we did not observe any labeled cells in layer 4C. This pattern of label was similar to that described in the case of one retrograde tracer injection into V2 by Van Essen et al. (1986) and may be the result of an injection into a unique compartment in V2 that receives monosynaptic input specifically from upper layer 2 as opposed to lower layer 2 and layer 3. The absence of disynaptic rabies label in layer $4 \mathrm{C}$ then would be expected, because axons of layer $4 \mathrm{C}$ cells do not project above layer 3B (Lachica et al., 1992; Yabuta and Callaway, 1998).

Together, these results make it likely that the labeled cells we observe in layer $4 \mathrm{C} \beta$ provide disynaptic input to the $\mathrm{CO}$ thick stripes of V2 via pyramidal cells in layer $4 \mathrm{~B}$ of $\mathrm{V} 1$ (Fig. $7 \mathrm{~B}$ ) (see Results). This is particularly significant because the thick stripes of V2 are known to project to MT (Shipp and Zeki, 1989b) and, thus, could provide input to MT from both M and P pathways.

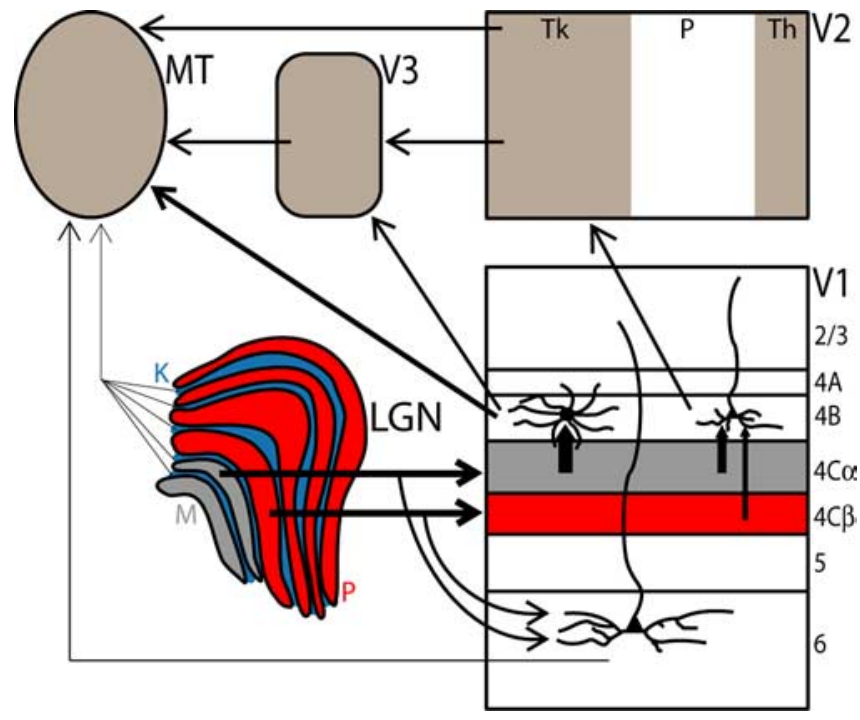

Figure 8. Multiple pathways from V1 to MT with varying degrees of M and P pathway convergence. Multiple pathways provide input to MT, with differing contributions from the M, $P$, and K pathways. A direct projection from LGN to MT is sparse and dominated by the K pathway (Sincich et al., 2004). A disynaptic connection from LGN to MT through layer 6 of V1 is more extensive and provides MT with convergent input from M and P pathways (Nassi et al., 2006). Trisynaptic input from LGN to MT via layer 4C of V1 is the most prominent and is dominated by the M pathway. Within a few more synapses, however, the P pathway contributes as well, likely via the $C O$ thick stripes of V2. See Discussion for additional details. Tk, Thick stripe; $P$, pale stripe; Th, thin stripe.

There is a chance, however, that the observed disynaptic label in $\mathrm{P}$-dominated layer $4 \mathrm{C} \beta$ resulted from injections involving pale stripes and not thick stripes (Sincich and Horton, 2002) or even subpopulations of cells within the thick stripes that do not project to MT, allowing for the possibility that MT does not receive mixed input from both $\mathrm{M}$ and $\mathrm{P}$ pathways indirectly through V2. Although the compartmental organization of projections from $\mathrm{V} 1$ to V2 recently has been called into question (Sincich and Horton, 2002), it is nevertheless clear from our observations that $\mathrm{MT}$ receives a substantial indirect input from $\mathrm{P}$-dominated layer $4 \mathrm{C} \beta$ and that the thick stripes of V2 remain the most likely candidate to relay this information to MT.

Previous work from our lab has shown conclusive evidence for input from LGN P cells to MT that is only two synapses away (Nassi et al., 2006). This pathway bypasses layer $4 C \beta$ and likely is mediated by layer 6 cells in V1. Although this disynaptic connection from LGN to MT is robust, it is nevertheless a minor connection compared with that through layers $4 \mathrm{C}$ and $4 \mathrm{~B}$ of $\mathrm{V} 1$ (Shipp and Zeki, 1989a). The results described here provide additional evidence for a $\mathrm{P}$ input to $\mathrm{MT}$ that involves the more prominent pathway through layer 4C. The connection from P-dominated layer $4 \mathrm{C} \beta$ to MT likely involves between three and five synapses, including a potential relay through the CO thick stripes of V2.

It is clear from these studies and previous work that MT receives input from multiple pathways with varying amounts of convergence among the $\mathrm{M}, \mathrm{P}$, and koniocellular $(\mathrm{K})$ processing streams (Fig. 8) (Sincich et al., 2004; Born and Bradley, 2005; Nassi et al., 2006). The pathways also differ in their number of synaptic relays and, thus, the speed with which they likely convey information to MT. Direct input from LGN to MT is sparse and dominated by the K pathway (Sincich et al., 2004). Disynaptic input from LGN to MT via layer 6 cells in V1 is more extensive and carries convergent input from $\mathrm{M}$ and $\mathrm{P}$ pathways (Nassi et al., 
2006). Trisynaptic input from LGN to MT via layer 4C of V1 is the most prominent and is dominated by the $\mathrm{M}$ pathway, yet within a few more synapses the $\mathrm{P}$ pathway contributes as well, likely via the CO thick stripes of V2. We suggest that each of these pathways is suited uniquely to convey visual information with varying degrees of spatial and temporal resolution as well as contrast sensitivity and color selectivity. Additional studies will be necessary to elucidate the functional contributions of each of these unique input pathways to MT and to understand better the complex interactions among the $\mathrm{M}, \mathrm{P}$, and $\mathrm{K}$ pathways of the primate visual system.

\section{References}

Blasdel GG, Fitzpatrick D (1984) Physiological organization of layer 4 in macaque striate cortex. J Neurosci 4:880-895.

Blasdel GG, Lund JS (1983) Termination of afferent axons in macaque striate cortex. J Neurosci 3:1389-1413.

Born RT, Bradley DC (2005) Structure and function of visual area MT. Annu Rev Neurosci 28:157-189.

Briggs F, Callaway EM (2001) Layer-specific input to distinct cell types in layer 6 of monkey primary visual cortex. J Neurosci 21:3600-3608.

Briggs F, Callaway EM (2005) Laminar patterns of local excitatory input to layer 5 neurons in macaque primary visual cortex. Cereb Cortex 15:479-488.

Burkhalter A, Felleman DJ, Newsome WT, Van Essen DC (1986) Anatomical and physiological asymmetries related to visual areas V3 and VP in macaque extrastriate cortex. Vision Res 26:63-80.

Callaway EM (1998) Local circuits in primary visual cortex of the macaque monkey. Annu Rev Neurosci 21:47-74.

Callaway EM (2005) Neural substrates within primary visual cortex for interactions between parallel visual pathways. Prog Brain Res 149:59-64.

DeYoe EA, Van Essen DC (1988) Concurrent processing streams in monkey visual cortex. Trends Neurosci 11:219-226.

Felleman DJ, Van Essen DC (1987) Receptive field properties of neurons in area V3 of macaque monkey extrastriate cortex. J Neurophysiol 57:889-920.

Felleman DJ, Van Essen DC (1991) Distributed hierarchical processing in the primate cerebral cortex. Cereb Cortex 1:1-47.

Felleman DJ, Burkhalter A, Van Essen DC (1997) Cortical connections of areas V3 and VP of macaque monkey extrastriate visual cortex. J Comp Neurol 379:21-47.

Gegenfurtner KR, Kiper DC, Levitt JB (1997) Functional properties of neurons in macaque area V3. J Neurophysiol 77:1906-1923.

Kelly RM, Strick PL (2000) Rabies as a transneuronal tracer of circuits in the central nervous system. J Neurosci Methods 103:63-71.

Kelly RM, Strick PL (2003) Cerebellar loops with motor cortex and prefrontal cortex of a nonhuman primate. J Neurosci 23:8432-8444.

Kennedy H, Bullier J (1985) A double-labeling investigation of the afferent connectivity to cortical areas V1 and V2 of the macaque monkey. J Neurosci 5:2815-2830.

Lachica EA, Beck PD, Casagrande VA (1992) Parallel pathways in macaque monkey striate cortex: anatomically defined columns in layer III. Proc Natl Acad Sci USA 89:3566-3570.

Livingstone M, Hubel D (1988) Segregation of form, color, movement, and depth: anatomy, physiology, and perception. Science 240:740-749.

Livingstone MS, Hubel DH (1987) Connections between layer 4B of area 17 and the thick cytochrome oxidase stripes of area 18 in the squirrel monkey. J Neurosci 7:3371-3377.

Lyon DC, Xu X, Casagrande VA, Stefansic JD, Shima D, Kaas JH (2002)
Optical imaging reveals retinotopic organization of dorsal V3 in New World owl monkeys. Proc Natl Acad Sci USA 99:15735-15742.

Maunsell JH, Van Essen DC (1983) The connections of the middle temporal visual area (MT) and their relationship to a cortical hierarchy in the macaque monkey. J Neurosci 3:2563-2586.

Merigan WH, Maunsell JH (1993) How parallel are the primate visual pathways? Annu Rev Neurosci 16:369-402.

Morimoto K, Hooper DC, Carbaugh H, Fu ZF, Koprowski H, Dietzschold B (1998) Rabies virus quasispecies: implications for pathogenesis. Proc Natl Acad Sci USA 95:3152-3156.

Nassi JJ, Lyon DC, Callaway EM (2006) The parvocellular LGN provides a robust disynaptic input to the visual motion area MT. Neuron 50:319-327.

Rockland KS (1992) Laminar distribution of neurons projecting from area $\mathrm{V} 1$ to V2 in macaque and squirrel monkeys. Cereb Cortex 2:38-47.

Sawatari A, Callaway EM (2000) Diversity and cell type specificity of local excitatory connections to neurons in layer $3 \mathrm{~B}$ of monkey primary visual cortex. Neuron 25:459-471.

Shipp S, Zeki S (1989a) The organization of connections between areas V5 and V1 in macaque monkey visual cortex. Eur J Neurosci 1:309-332.

Shipp S, Zeki S (1989b) The organization of connections between areas V5 and V2 in macaque monkey visual cortex. Eur J Neurosci 1:333-354.

Sincich LC, Horton JC (2002) Divided by cytochrome oxidase: a map of the projections from V1 to V2 in macaques. Science 295:1734-1737.

Sincich LC, Horton JC (2003) Independent projection streams from macaque striate cortex to the second visual area and middle temporal area. J Neurosci 23:5684-5692.

Sincich LC, Horton JC (2005) The circuitry of V1 and V2: integration of color, form, and motion. Annu Rev Neurosci 28:303-326.

Sincich LC, Park KF, Wohlgemuth MJ, Horton JC (2004) Bypassing V1: a direct geniculate input to area MT. Nat Neurosci 7:1123-1128.

Sincich LC, Jocson CM, Horton JC (2006) Neurons in V1 patch columns project to V2 thin stripes. Cereb Cortex, in press.

Tootell RB, Hamilton SL, Silverman MS (1985) Topography of cytochrome oxidase activity in owl monkey cortex. J Neurosci 5:2786-2800.

Ugolini G (1995) Specificity of rabies virus as a transneuronal tracer of motor networks: transfer from hypoglossal motoneurons to connected second-order and higher order central nervous system cell groups. J Comp Neurol 356:457-480.

Van Essen DC, Deyoe EA (1994) Concurrent processing in the primate visual cortex. In: The cognitive neuroscience (Gazzuniga MS, ed), pp 383400. Cambridge, MA: MIT.

Van Essen DC, Maunsell JH, Bixby JL (1981) The middle temporal visual area in the macaque: myeloarchitecture, connections, functional properties and topographic organization. J Comp Neurol 199:293-326.

Van Essen DC, Newsome WT, Maunsell JH, Bixby JL (1986) The projections from striate cortex (V1) to areas V2 and V3 in the macaque monkey: asymmetries, areal boundaries, and patchy connections. J Comp Neurol 244:451-480.

Xiao Y, Felleman DJ (2004) Projections from primary visual cortex to cytochrome oxidase thin stripes and interstripes of macaque visual area 2. Proc Natl Acad Sci USA 101:7147-7151.

Yabuta NH, Callaway EM (1998) Functional streams and local connections of layer $4 \mathrm{C}$ neurons in primary visual cortex of the macaque monkey. J Neurosci 18:9489-9499.

Yabuta NH, Sawatari A, Callaway EM (2001) Two functional channels from primary visual cortex to dorsal visual cortical areas. Science 292:297-300.

Zeki S, Shipp S (1988) The functional logic of cortical connections. Nature 335:311-317. 